speaking, protective equipment has been largely adopted by the miners themselves. It is worth knowing that Great Britain is not the only country adopting protective equipment, the article by Leprince-Ringuet on miners' hats appearing in the Annales des Mines of Paris proving this point. The various representatives of the local committees are doing good work in popularizing the use of protective equipment, and the subject of falls of ground is making fair progress, considering the inherent difficulties of the subject.

\section{Radio Relay Services}

RADro relay is much more common abroad, where it is regarded as a public service, than in Great Britain. In a pamphlet written by G. S. Lucas and E. S. Hall of the Research Department of the British Thomson-Houston Co., Ltd., a description is given of the radio relay equipment built and designed for the Midland Relay Services, Ltd. It is suitable for 300 subscribers but could easily be adapted to suit 1,000 or more subscribers. It has four radio receivers with their aerial equipment, and a short-wave receiver. The aerial equipment depends upon the locality and conditions of reception. For the installation carried out at Rugby, two vertical aerials about 25 feet in length are used for local reception. For long-distance work a horizontal aerial 100 feet long and 50 feet high is used. For use on short-wave reception a special $V$ doublet aerial has been installed. Two of the receivers are suitable for B.B.C. transmission and two for long-distance Continental programmes. The advantages offered to the public by this service are the replacement of aerials by simple overhead wires. The installation of only a simple speaker unit in the house is required; no power supply or battery is necessary. The main control station is under constant supervision and the receivers are adjusted for the best working conditions. The radio relay station is capable of relaying two or three independent programmes to all subscribers. All the vital points of the system are duplicated and the organization can deal quickly and effectively with faults and complaints as they arise.

\section{Telephone Development in Birmingham}

A LARGe and imposing building called Telephone House has been built in Birmingham to accommodate the telephone equipment for the city and also the Post Office and engineering and administrative staffs. A description of the telephone equipment required for the trunk, toll and central exchanges which were installed by Siemens Brothers and Co., Ltd., of Woolwich, to the order of the Post Office, is given in the September supplement of the Siemens Magazine. The introduction of the maximum fee of one shilling for three minutes on all inland trunk calls made after 7 o'clock in the evening has made the trunk service very popular, and the more recent introduction of a half-crown maximum for a three minute trunk call between any two places on the mainland of Great Britain will still further increase the amount of trunk traffic. Outside London, Birmingham is the most important telephone centre in Great Britain.
It is connected by direct trunk lines with all other zone centres and, in addition, forms an important link in the alternative trunk routes between London and other zone centres such as Liverpool, Manchester, Leeds, Sheffield, Nottingham and Leicester. The new trunk and toll equipment has been planned to meet the long distance (tr unk) and the short distance (toll) traffic anticipated in the Birmingham district during the next few years. Since 1930 the development of the trunk traffic has exceeded all expectations. There have been installed in the building 367 switchboards, and in addition a centralized manual board for the whole of the Birmingham area. In the same building also a 5,700 line full automatic equipment for the central exchange is being installed. Two motor generator sets driven from the 400 volt 3 phase 50 cycle public supply mains, with an output of 1,600 amperes at 57 volts, are being used.

\section{Research in Mental Diseases}

THe Annual Report, 1935-36, of the Joint Board of Research for Mental Disease of the City and University of Birmingham contains an account of much painstaking and laborious work (Birmingham : The University, 1936). The occurrence and distribution of 80 named varieties of micro-organisms are tabulated; 6,565 specimens were examined. Somewhat optimistically the report claims to have solved the problem of the cause of mental disease, since "it appears that mental disorder cannot be classed as an infectious disease, nor as a metabolic disorder, but that it is a clinical resultant of infectious and metabolic disorders acting during any period of the ante- and post-natal life of the individual, thus: determining the character and onset of the mental symptoms". Also, "The functional disturbances of the central nervous system responsible for the symptoms of mental disorder, can be clinically and pathologically associated with local disturbances of the vascular supply to certain vital centres of the brain". It is true that the pathology of some brain diseases that cause mental disorder is well established, for example, encephalitis, syphilis, tumours; but there still remains a host of disorders, ranging through hysteria and the anxiety and obsessional states to schizophrenic personalities, and cyclothymia. or manic-depressive conditions and paranoia, that have so far defied the laboratory expert.

\section{False Killer Whales in South Africa}

Dr. Leonard GILI, in the Report of the South African Museum for the year 1935 (1936, p. 10), recounts another of those mass strandings of Pseudorca crassidens which have become so frequent since the reappearance of the species in the Dornoch Firth. The school came ashore at Mamre, about fifty miles north of Cape Town, and the occurrence was peculiar because of the large number of whales stranded, about three hundred, and because they came ashore not on sand but on jagged rocks. But a common fcature of the strandings has been, as here, that the whales appear to have been trapped by a falling tide in channels cut off from the open sea by sand-banks. The Mamre stranding took place 